\title{
FREQUÊNCIA DE ANTICORPOS ANTI-TOXOPLASMA GONDII EM CÃES COM SINAIS CLÍNICOS COMPATÍVEIS COM TOXOPLASMOSE
}

\section{FREQUENCY OF ANTI-TOXOPLASMA GONDII ANTIBODIES IN DOGS WITH CLINICAL SIGNS CONSISTENT WITH TOXOPLASMOSIS}

\author{
Fernanda Pinto Ferreira ${ }^{*}$ \\ Ana Carolina Miura ${ }^{1}$ \\ Marcelle Mareze ${ }^{1}$ \\ João Luis Garcia ${ }^{1}$ \\ Roberta Lemos Freire ${ }^{1}$ \\ Italmar Teodorico Navarro ${ }^{1}$ \\ ${ }^{1}$ Universidade Estadual de Londrina, Londrina, PR, Brasil. \\ *Autora para contato - fernandaferreira@uel.br
}

\section{Resumo:}

O objetivo deste trabalho foi detectar anticorpos contra T. gondii em cães com sinais clínicos compatíveis com toxoplasmose atendidos em um Hospital Veterinário. Foram submetidos a sorologia 598 cães no período de 1993 a 2013. A pesquisa de anticorpos da classe IgG contra T. gondii foi realizada pela Reação de Imunofluorescência Indireta (RIFI); amostras com título $\geq 16$ foram consideradas positivas. Entre os cães com sinais clínicos, 259 (43,31\%) foram soropositivos para $T$. gondii com títulos variando de 16 a 4096; já entre os animais hígidos, 79 (22,25\%) foram reagentes. Os sinais mais evidentes foram os neurológicos $(30,43 \%)$ e uveíte $(8,03 \%)$. Entre as variáveis raça, sexo e idade, apenas a última exerceu influência sobre os resultados observados, com maior frequência de soropositivos em cães idosos.

Palavras-chave: caninos; RIFI; sinais clínicos; sorologia; Toxoplasma gondii; zoonose.

\begin{abstract}
:
The aim of this study was to detect antibodies against $T$. gondii in dogs with clinical signs compatible with toxoplasmosis attended in a veterinary hospital. A serological survey was performed in 598 dogs from 1993 to 2013. The IgG antibodies survey against T. gondii was carried out by means of Indirect Fluorescence Antibodies Test (IFAT); samples with titers $\geq 16$ were considered positive. Among the dogs with clinical signs, $259(43,31 \%)$ were positive for $T$. gondii with titers varying between 16 to 4096; among the healthy animals, $79(22.25 \%)$ were reagents. The most frequent signals were: neurological (30.43\%) and uveitis (8.03\%). Among variables race, gender, and age, only the last one affected the observed results with greater frequency f seropositive in elderly dogs.

Keywords: clinical signs; dogs; IFAT; serology; Toxoplasma gondii; zoonosis.
\end{abstract}

Enviado em: 02 maio 2016

Aceito em: 14 setembro 2016

\section{Introdução}

Toxoplasma gondii é um protozoário intracelular obrigatório que apresenta distribuição cosmopolita e caráter oportunista. Os animais homeotérmicos são considerados hospedeiros intermediários e os felídeos, os definitivos; nestes os oocistos do parasito se desenvolvem e são eliminados com as 
fezes para posterior esporulação no ambiente. Em ambos os hospedeiros são encontradas as formas de taquizoítas na fase aguda e de cistos e bradizoítas na fase crônica ${ }^{(1,2)}$. A infecção em humanos e animais ocorre principalmente pela ingestão de alimentos contaminados com cistos teciduais ou oocistos esporulados e por via transplacentária ${ }^{(3)}$.

As manifestações clínicas da toxoplasmose canina são inespecíficas, similares a outras doenças e envolvem vários sistemas como: nervoso, reprodutivo, digestório, respiratório, ocular, muscular, hematopoiético, hepático e cardiovascular ${ }^{(4-6)}$. A doença ocorre, normalmente, secundária a infecções virais como a cinomose ou a outros agentes imunossupressores ${ }^{(7-9)}$.

Segundo Moura et al. ${ }^{(10)}$, a soropositividade a T. gondii em cães é relativamente alta no Brasil e as taxas variam de $20,8 \%{ }^{(11)}$ a $76,4 \%{ }^{(12)}$, de acordo com a região estudada e/ou técnica diagnóstica empregada.

Do ponto de vista da saúde pública, a infecção em cães tem grande importância epidemiológica. Haja vista que estes compartilham o mesmo "habitat" com os humanos e podem indicar que a área envolvida representa um nicho ecológico para o parasito e, consequentemente, um potencial risco de infecção para população humana ${ }^{(10,13,14)}$.

O objetivo deste trabalho foi detectar anticorpos contra $T$. gondii em cães com sinais clínicos compatíveis com toxoplasmose atendidos em um Hospital Veterinário Escola, no Paraná, sul do Brasil.

\section{Material e Métodos}

Entre 1993 e 2013 foram solicitados exames sorológicos de 598 cães com sinais clínicos compatíveis com toxoplasmose, atendidos no Hospital Veterinário Escola em Londrina. As amostras de sangue foram obtidas por punção da veia cefálica ou jugular, acondicionadas em tubos de ensaio e encaminhadas ao Laboratório de Zoonoses e Saúde Pública Veterinária da Universidade Estadual de Londrina (UEL). Após a retração do coágulo, o soro foi acondicionado em microtubos de polietileno e mantido a $-20{ }^{\circ} \mathrm{C}$ até o processamento das amostras.

As amostras foram examinadas para detecção de anticorpos IgG contra Toxoplasma gondii por meio da reação de imunofluorescência indireta (RIFI) de acordo com Camargo ${ }^{(15)}$. Foram utilizados como antígeno a cepa RH e o conjugado anti-IgG de cão (Fluoresceinisothiocyanate - Sigma®). Primeiramente, foi realizada uma triagem nas diluições 1:16 e 1:64, sendo consideradas positivas amostras com título $\geq 16^{(16)}$. Após a triagem foi realizada diluição completa, na base quatro, até a amostra tornar-se negativa. Controles positivos e negativos, previamente conhecidos, foram incluídos em cada análise (1:16).

Informações quanto a idade, sexo, raça e manifestações clínicas foram obtidas dos prontuários dos animais. Foram considerados filhotes os animais com idade entre um dia e um ano, adultos acima de um ano até oito anos e idosos acima de oito anos.

Para a análise das variáveis estudadas e comparações das proporções utilizou-se o teste de quiquadrado ou Exato de Fisher, com nível de significância de 5\%.

\section{Resultados}

Dos 598 cães com sinais clínicos, 259 (43,31\%) foram positivos na RIFI anti-T. gondii; 351 (58,69\%) amostras provinham de cães com raça e $247(41,30 \%)$ de cães sem raça definida. Quanto ao sexo, 303 $(50,67 \%)$ eram fêmeas e $295(49,33 \%)$ machos. Com relação à idade, $113(18,90 \%)$ eram filhotes, $433(72,41 \%)$ adultos e $52(8,69 \%)$ idosos. A distribuição dos animais sororreagentes para T. gondii em relação às variáveis idade, sexo e raça está descrita na Tabela 1. A faixa etária variou de 30 dias a 
17 anos, sendo que a soropositividade foi mais frequente nos animais com idade acima de oito anos $(61,54 \% ; p=0,0014)$. Não houve diferença estatisticamente significativa $(\mathrm{p} \geq 0,05)$ em relação ao sexo e à raça. Com relação ao título de anticorpos, houve variação entre 16 e 4096, sendo mais comum o título 16, com frequência de 37,45\% (97/259) (Tabela 2).

Tabela 1. Distribuição de amostras sorológicas positivas para Toxoplasma gondii (IgG) pela técnica de Imunofluorescência Indireta de 598 cães atendidos em um Hospital Veterinário Escola, Londrina, PR com sinais clínicos compatíveis com toxoplasmose, segundo as variáveis idade, sexo e raça, de 1993 a 2013

\begin{tabular}{lll}
\hline Variáveis & Positivos/Total (\%) & Valor de p \\
\hline \hline Idade & $36 / 113(31,83)$ & 0.0014 \\
Filhote (1 dia - 1 ano) & $191 / 433(44,11)$ & \\
Adulto (1 ano - 8 anos) & $32 / 52(61,54)$ & \\
Idoso (Acima de 8 anos) & $132 / 303(43,56)$ & 0,9647 \\
\hline Sexo & $127 / 295(43,05)$ & \\
$\quad$ Fêmea & & \\
Macho & $142 / 351(40,46)$ & 0,1185 \\
\hline Raça & $117 / 247(47,37)$ & \\
Com Raça & $\mathbf{2 5 9 / 5 9 8 ( 4 3 , 3 1 )}$ & \\
Sem Raça &
\end{tabular}

Tabela 2. Distribuição dos títulos de anticorpos anti-Toxoplasma gondii (IgG) obtidos pela Reação de Imunofluorescência Inidreta (IgG), em soro de cães com sinais clínicos. Londrina, PR, de 1993 a 2013

\begin{tabular}{ccc}
\hline Título de Anticorpos & Positivos & $(\%)$ \\
\hline \hline 16 & 97 & 37,45 \\
64 & 90 & 34,75 \\
256 & 42 & 16,22 \\
1024 & 14 & 5,41 \\
4096 & 16 & 6,17 \\
\hline Total & $\mathbf{2 5 9}$ & $\mathbf{1 0 0}$ \\
\hline
\end{tabular}

Tabela 3. Frequência de sinais clínicos em cães soropositivos para Toxoplasma gondii (IgG) pela técnica de Imunofluorescência Indireta, Londrina, PR, de 1993 a 2013

\begin{tabular}{lll}
\hline Sinais clínicos & Positivos/Total (\%) & Valor de p \\
\hline \hline Sinais neurológicos* & $182 / 217(83,87)$ & $\mathrm{p}<0,0001$ \\
Uveíte & $48 / 115(41,74)$ & \\
Sinais reprodutivos** & $25 / 77(32,46)$ & \\
Sinais respiratórios*** & $4 / 6(66,66)$ & \\
\hline Total & $\mathbf{2 5 9 / 5 9 8 ( 4 3 , 3 1 )}$ &
\end{tabular}

${ }^{*}$ Convulsão, ataxia, paresia, plegia, mioclonias, mialgia e tremores. ${ }^{* *}$ Abortamento, natimortalidade e nascimento prematuro. *** Secreção nasal e tosse. 
Na Tabela 3 estão apresentados os sinais clínicos dos cães submetidos à RIFI. Observou-se maior frequência de sinais neurológicos $(\mathrm{p}<0,0001)$, como convulsão, ataxia, paresia e plegias, quando comparados com os sinais oftálmicos, reprodutivos e respiratórios, também encontrados no presente trabalho.

\section{Discussão}

Estudos recentes no Brasil mostram uma variação na frequência de soropositividade para T. gondii em cães de $11,50 \%$ a $88,52 \%^{(16-21)}$. Essa variação de resultados pode estar relacionada às diferentes técnicas utilizadas e pontos de corte.

No presente trabalho, foram encontrados anticorpos contra T. gondii em 43,31\% (259/598) dos cães testados, resultado inferior aos reportados por Freire et al. ${ }^{(22)}$ e Zulpo et al. ${ }^{(23)}$, que encontraram frequência de 75,98\% (193/254) e 50,89\% (57/112), respectivamente, ambos em cães atendidos no Hospital Veterinário Universitário em Londrina, no Paraná, utilizando mesma técnica. Esta queda no número de animais positivos no decorrer dos anos pode estar associada à popularização da ração animal e diminuição do hábito de oferecer vísceras e tecidos crus aos cães. Moura et al. ${ }^{(11)}$ e Silva et al. ${ }^{(24)}$, ao avaliarem fatores de risco para a infecção por $T$. gondii, encontraram prevalências de $38,1 \%$ (45/118) e 74,2\% (66/89), respectivamente, e constataram que a alimentação à base de dieta caseira é um fator predisponente para a infecção.

Neste estudo, não foi observada diferença estatística significativa entre as variáveis sexo e raça, o que corrobora trabalhos prévios ${ }^{(11,25,26)}$. Com relação à faixa etária, foi observada maior proporção de cães soropositivos em adultos e idosos, fato este também observado por Navarro et al. ${ }^{(27)}$ e Barbosa et al. ${ }^{(28)}$. A prevalência de infecção por T. gondii tem tendência a ser maior em animais adultos, uma vez que, com o decorrer dos anos, existe maior probabilidade do cão entrar em contato com as fontes de infecção $0^{(12,29)}$.

A maioria dos títulos de anticorpos nos caninos apresentou-se entre $16(37,45 \%)$ e $64(34,75)$, resultados similares aos obtidos por Garcia et al. ${ }^{(14)}$, que observaram frequências de $31,4 \%$ e $38,4 \%$ para títulos 16 e 64, respectivamente.

No período de 2009 a 2010, em um Hospital Veterinário do interior de São Paulo, Langoni et al. ${ }^{(30)}$ avaliaram 50 cães internados, com sinais neurológicos como ataxia, convulsões, alteração de comportamento, paralisia, paraplegia e tremores. Do total de animais, $11(22,00 \%)$ foram positivos na RIFI para $T$. gondii, valor inferior ao encontrado neste estudo, no qual 30,43\% (182/598) dos animais foram reagentes e apresentaram sinais neurológicos semelhantes (Tabela 3). De acordo com Dubey e Lappin ${ }^{(31)}$, o quadro neurológico depende da localização do parasito no cérebro, cerebelo e medula espinhal, o que explica a diversidade de sinais neurológicos.

Bresciani et al. ${ }^{(32)}$ infectaram cinco cadelas gestantes, sorologicamente negativas, com oocistos ou taquizoítas de $T$. gondii e observaram manifestações reprodutivas, tais como abortamento, nascimento prematuro e natimortalidade. No presente trabalho, foram observados sinais semelhantes em $4,18 \%$ (25/598) dos animais reagentes. De acordo com Helley et al. ${ }^{(33)}$, a infecção toxoplásmica pode provocar abortamento em cadelas gestantes, além de mortalidade em filhotes do $4^{\circ}$ ao $75^{\circ}$ dias pós-nascimento.

Dos animais analisados, 19,23\% (115/598) apresentaram uveíte como principal sinal clínico; destes, $8,03 \%$ (48/598) foram reagentes para T. gondii. Esse processo inflamatório é comum na toxoplasmose e, geralmente, é induzido pela citólise decorrente da replicação dos taquizoítas e deposição de imunocomplexos via intraocular ${ }^{(34)}$. Abreu et al. ${ }^{(35)}$, em um estudo em Londrina, PR, com nove cães infectados experimentalmente por diferentes cepas de $T$. gondii, observaram alterações no sistema ocular, tais como áreas de hiperrefletividade, edema de pupila, edema perivascular temporal, exsudato peripapilar bilateral, hipopigmentação e ainda infiltrado inflamatório em íris e coróide, estruturas componentes da úvea. 


\section{Conclusões}

A frequência de animais reagentes na RIFI anti- $T$. gondii foi de 43,31\% e mostra a relevância de uma abordagem minuciosa ao paciente a fim de se realizar um diagnóstico precoce e preciso. Os sinais clínicos da toxoplasmose são inespecíficos, comuns a outras doenças, tais como a cinomose, brucelose e leishmaniose, que apresentam maior gravidade ao cão e grande importância à Saúde pública, respectivamente. É importante salientar que a RIFI ainda serve como uma ferramenta de diagnóstico; no entanto, é imprescindível a associação com outros exames, tais como métodos moleculares, histopatologia e imuno-histoquímica, entre outros.

\section{Referências}

1. Miller NL, Frenkel JK \& Dubey, JP. Oral infections with Toxoplasma cysts and oocysts in felines, other mammals and birds. Journal of Parasitology 1972;58(5):928-937.

2. Dubey JP. Toxoplasmosis of Animals and Humans. $2^{\text {nd }}$ ed. CRC Press, Boca Raton. 2010. p. 5-7.English.

3. Dubey JP. Strategies to reduce transmission of Toxoplasma gondii to animals and humans. Veterinary Parasitology 1996;64:65-70.

4. Mineo TWP, Silva DAO, Näslund K, Björkman C, Uggla A \& Mineo JR. Toxoplasma gondiiand Neospora caninum serological status of different canine populations from Uberlândia, Minas Gerais. Arquivo Brasileiro de Medicina Veterinária e Zootecnia. 2004;56(3):414-417.

5. Silva AV, Pezerico SB, Lima VY, Moretti L, Pinheiro JP, Tanaka EM, Ribeiro MG \& Langoni H. Genotyping of Toxoplasma gondii strains isolated from dogs with neurological signs. Veterinary Parasitology. 2005;127:2327.

6. Galvão ALB, Vasconcellos AL, Navarro IT \& Bresciani KDS. Aspectos da toxoplasmose na clínica de pequenos animais. Semina, Ciências Agrárias 2014;35(1):393-410.

7. Moretti LD, Ueno TE, Ribeiro MR, Aguiar DM, Paes AC, Pezerico SB \& Silva AV. Toxoplasmose em cães co-infectados com o vírus da cinomose. Semina, Ciências Agrárias. 2002;23(1):85-91.

8. Dubey JP, Ross AD \& Fritz D. Clinical Toxoplasma gondii, Hammondia heydorni, and Sarcocystis sp. infections in dogs. Veterinary Parasitology. 2003;45:141-146.

9. Headley SA, Alfieri AA, Fritzen JT, Garcia JL, Weissenböck H, DaSilva AP, Bodnar L, Okano W \& Alfieri AF. Concomitant canine distemper, infectious canine hepatitis, canine parvoviral enteritis, canine infectious tracheobronchitis, and toxoplasmosis in a puppy. The Journal Veterinary Diagnostic Investigation. 2013;25(1):129-135.

10. Moura AB, Souza AP, Sartor AA, Bellato V, Teixeira EB, Pisetta GM \& Heusser Junior A. Ocorrência de anticorpos e fatores de risco para infecção por Toxoplasma gondii em cães, nas cidades de Lages e Balneário Camboriú, Santa Catarina, Brasil. Revista Brasileira de Parasitologia Veterinária. 2009;18(3):52-56.

11. Romanelli PR, Freire RL, Vidotto O, Marana ERM, Ogawa L, De Paula VSO, Garcia JL \& Navarro IT. Prevalence of Neospora caninum and Toxoplasma gondii in sheep and dogs from Guarapuava farms, Paraná State, Brazil. Research Veterinary Science. 2007;82:202-207.

12. Canon-Franco WA, Bergamaschi DP, Labruna MB, Camargo LM, Silva JC, Pinter A \& Gennari SM. Occurrence of anti-Toxoplasma gondii antibodies in dogs in the urban area of Monte Negro, Rondônia, Brazil. Veterinary Research Communications. 2004;28(2):113-118. 
13. Germano PML, Erbolato EB \& Ishizuka MJH. Estudo sorológico da toxoplasmose canina, pela prova de imunofluorescência indireta, na cidade de Campinas, 1981. Revista Faculdade Medicina Veterinária e Zootecnia USP. 1985;22:53-58.

14. Garcia JL, Navarro IT, Ogawa L \& Oliveira RC. Soroprevalência de Toxoplasma gondii em suínos, bovinos, ovinos e equinos, e sua correlação com humanos, felinos e caninos, oriundos de propriedades rurais do norte do Paraná, Brasil. Ciência Rural. 1999;29(1):91-97.

15. Camargo ME Improved technique of indirect immunofluorescence for serological diagnosis of toxoplasmosis. Revista do Instituto de Medicina Tropical de São Paulo. 1964;6:117-118.

16. Caldart ET, Constantino C, Pasquali AKS, Benitez AN, Hamada FN, Dias RCF, Rorato-Nascimento AM, Marana ERM, Navarro IT, Mascarenhas NMF, Freitas JC, Freire RL. Zoonosis in dogs and cats attended by the Birth Control Project: Toxoplasma gondii, Leishmania spp. and Leptospira spp., serodiagnosis and epidemiology. Semina, Ciências Agrárias. 2015;36(1):253-266.

17. Santos TR. Prevalência de anticorpos anti-Toxoplasma gondii em bovinos, cães e humanos da região do estado do Mato Grosso. Dissertação de Mestrado, Faculdade de Ciências Agrárias e Veterinárias, Universidade Estadual Paulista, Jaboticabal, SP. 2008;71p.

18. Guimarães AM, Rocha CMBM, Oliveira TMFS, Rosado IR, Morais LG \& Santos RRD. Fatores associados à soropositividade para Babesia, Toxoplasma, Neospora e Leishmania em cães atendidos em nove clínicas veterinárias do município de Lavras, MG. Revista Brasileira de Parasitologia Veterinária. 2009;18 (1):49-53.

19. Lopes MG, Mendonça IL, Fortes KP, Amaku M, Pena HFJ \& Gennari SM. Presence of antibodies against Toxoplasma gondii, Neosporacaninumand Leishmaniainfantumin dogs from Piauí. Revista Brasileira de.Parasitologia Veterinária 2011;20(2):111-114.

20. Silva Filho MF, Tamekuni K, Toledo RS, Dias RCF, Lopes-Mori FMR, Mitsuka-Breganó R, ThomazSoccol V, Garcia JL, Freire RL, Vidotto O \& Navarro IT. Infection by Toxoplasma gondii and Leishmania spp. in humans and dogs from rural settlements in northern Paraná State, Brazil. Semina, Ciências Agrárias. 2012;33(2):3251-3264.

21. Dantas SBA, Fernandes ARF, Souza Neto OL, Clebert RAM \& Azevedo SS. Ocorrência e fatores de risco associados às infecções por Toxoplasma gondii e Neospora caninum em cães no município de Natal, Estado do Rio Grande do Norte, Nordeste do Brasil. Ciência Rural. 2013;43(11):2042-2048.

22. Freire RL, Navarro IT, Vidotto O, Tudury EA \& Vianna CC. Prevalência de anticorpos anti-Toxoplasma gondii em cães atendidos no Hospital Veterinário da UEL/PR. Semina, Ciências Agrárias. 1992;13(1):66-692.

23. Zulpo DL, Leite JHAC, Cunha IAL, Barros LD, Taroda A, Camargo Júnior VC, Santos HLEPL \& Garcia JL Ocorrência de anticorpos contra Leishmania spp., Neospora caninum e Toxoplasma gondii em soros de cães atendidos no Hospital Veterinário da Universidade Estadual de Londrina/PR. Semina, Ciências Agrárias. 2012;33(5):1897-1906.

24. Silva RC, Lima VY, Tanaka EM, Silva AV, Souza LC \&Langoni H. Risk factors and presence of antibodies to Toxoplasma gondii in dogs from the coast of São Paulo, Brazil. Pesquisa Veterinária Brasileira. 2010; 30(2):61-166.

25. Varandas NP, Rached PA, Costa GHN, Souza LM, Castagnolli KC \& Costa AJ. Frequência de anticorpos anti-Neospora caninum e anti-Toxoplasma gondii em cães da região nordeste do Estado de São Paulo: correlação com neuropatias. Semina,Ciências Agrárias. 2012;22(1):105-111.

26. Bresciani KDS, Costa AJ, Nunes CM, Serrano ACM, Moura AB, Stobbe NS, Perri SHV, Dias RA \& Gennari SM. Ocorrência de anticorpos contra Neospora caninum e Toxoplasma gondii e estudo de fatores de risco em cães de Araçatuba/SP. Ars Veterinária. 2007;23(1):40-46.

27. Navarro IT, Freire RL, Vidotto O, Ogawa L \& Kano FS. Estudo comparativo entre soro e plasma na pesquisa de anticorpos anti-Toxoplasma gondii pela técnica de imunofluorescência indireta em cães atendidos no Hospital 
Veterinário da Universidade Estadual de Londrina/PR, 1996. Semina, Ciências Agrárias. 1997;18(1):15-21.

28. Barbosa MVF, Guimarães JE, Almeida MAO, Gondim LFP \& Regis GB. Frequência de anticorpos IgG antiToxoplasma gondii em soros de cães errantes da cidade de Salvador/Bahia, Brasil. Brazil Journal Veterinary Research Animal. Science. 2003;40(6):457-465.

29. Azevedo SS, Batista CSA, Vasconcellos SA, Aguiar DM, Ragozo AMA, Rodrigues AAR, Alves CJ \&Gennari SM.Seroepidemiology of Toxoplasma gondiiand Neospora caninum in dogs from the state of Paraíba, Northeast region of Brazil. Research in Veterinary Science. 2005;79(1):51-56.

30. Langoni H, Mateuci G, Medici B, Camossi LG, Richini-Pereira VB \& Silva RC. Detection and molecular analysis of Toxoplasma gondii and Neospora caninum from dogs with neurological disorders. Revista da Sociedade Brasileira de Medicina Tropical. 2012;45(3):365-368.

31. Dubey JP \& Lappin MR. Toxoplasmosis and neosporosis, In: Greene C.E. (Ed.), Infectious Diseases of the Dog and Cat. $3^{\text {rd }}$ ed. Elsevier, St Louis. 2006. p.754-775.

32. Bresciani KDS, Toniollo GH, Costa AJ, Sabatini GA \& Moraes FR. Clinical, parasitological and obstetric observations in pregnant bitches with experimental toxoplasmosis. Ciência Rural 2001;31(6):1039-1043.

33. Helley DM. Toxoplasmosis. Journal Small Animal Practice. 1963;4:435-446.

34.Chavkin MJ, Lappin MR, Powel CC, Cooper CM, Muñana K.R, Howard LH. Toxoplasma gondii-specific antibodies in the aqueous humor of cats with toxoplasmosis. American Journal of Veterinary Research. 1994;55(9):1244-1249.

35. Abreu CB, Navarro IT, Reis ACF, Souza MSB, Machado R, Marana ERM, Prudêncio LB, Mattos MR \& Tsutsui VS. Toxoplasmose ocular em cães jovens inoculados com Toxoplasma gondii. Ciência Rural 2002;32(5):807-812. 